\title{
Decision, Implementation, and Confirmation: Experiences of Instructors behind Tourism and Hospitality MOOCs
}

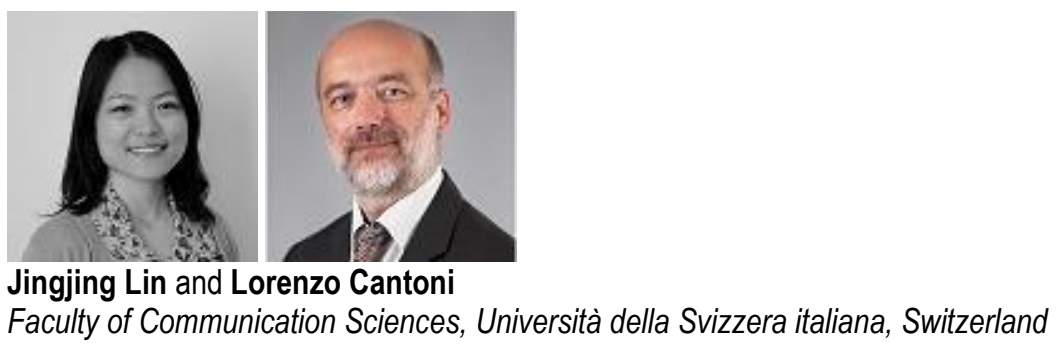

\begin{abstract}
As the popularity of Massive Open Online Courses (MOOCs) continues to grow, studies are emerging to investigate various topics in this area. Most have focused on the learners' perspective, leaving a gap in the literature about MOOC instructors. The current research-conducted in the field of tourism and hospitality-explored early experiences of MOOC instructors as they progressed through three stages of the innovation-decision process: decision, implementation, and confirmation. The tourism and hospitality field was chosen because its related industries contribute significantly to global employment, and training is one of their critical success factors. MOOCs possess a good potential to benefit tourism and hospitality education, yet tourism and hospitality MOOCs are under-researched. Semi-structured interviews were conducted with six instructors who offered tourism and hospitality MOOCs between 2008 and 2015. Findings revealed that: (1) the instructors' decisions to offer MOOCs were mostly influenced by their institutes' interests in MOOCs; (2) when the instructors implemented MOOCs, a pattern of action emerged, which included six phases and one cross-phase elementprepare, design, develop, launch, deliver, and evaluate-and across phases-support and train; (3) most instructors chose to avoid risk in their adoption and implementation of the MOOCs, staying away from innovative teaching or learning activities such as peer-review assessments and collaborative activities; and (4) half of the instructors intended to repeat the experience of teaching in the MOOCs format in the future.
\end{abstract}

Keywords: MOOCs, instructors, diffusion of innovation, innovation decision process, motivation, tourism, hospitality

\section{Introduction}

The term MOOC (Massive Open Online Course) was coined in 2008 to describe the online course Connectivism and Connective Knowledge, which was offered to 24, for-credit students at the 
University of Manitoba but also opened to 2,200 additional participants from around the globe (Siemens, 2013). Since that time, the proliferation of MOOCs has been beyond imagination. In 2015, the number of MOOCs totalled 4,550 provisions and involved more than 570 universities-reaching 35 million learners (Cook, 2016).

Despite the fast development of MOOCs, their offerings in the field of tourism and hospitality (shortened as T\&H below) remain scarce (Tracey, Murphy, \& Horton-Tognazzini, 2016), especially when compared with other subjects covered by MOOCs. This is somehow strange, if one considers the peculiarities of T\&H field-e.g., high turnover, seasonality, new global challenges-which make the use of information communication technologies particularly relevant in order to provide flexible training and upskilling opportunities to very diverse audiences in the concerned industries (Cantoni, Kalbaska, \& Inversini, 2009; Miralbell, Cantoni, \& Kalbaska, 2014).

There were 51 T\&H MOOCs by 2015, with 23 provided by higher education institutes (HEIs), mostly in the English language (18 of 23). A study by Ryan, Horton-Tognazzini, and Williams (2016) confirmed the dearth of T\&H MOOCs. The first MOOC dedicated to T\&H topics was Tourism Industry Analysis, offered on the Canvas Network platform by Central Florida University in 2013. In 2014, another MOOC offered by HEIs in the field of T\&H was published, Introduction to Wines 101 by Taylor's University (in Malaysia). In 2015, 15 T\&H MOOCs from HEIs appeared, followed by seven more in 2016, and five more in 2017 (counting only MOOCs offered in English).

In October 2015, the first MOOC titled eTourism: Communication Perspectives by the Università della Svizzera italiana (Switzerland) joined the other offerings of T\&H MOOCs and was launched on the iversity platform (https://iversity.org). The initiative, for the university, was an experiment out of the motivations of social corporate responsibility, developing the public relations and brand marketing; meanwhile, for the faculty, it was an opportunity to expand the existing T\&H research into the domain of eLearning. MOOCs in T\&H since then had become an independent research line in the university. As members of the development team, we have been through a full process of designing and implementing the $\mathrm{MOOC}$ as providers. The experience inspired a research problem: What are other instructors' experiences of providing T\&H MOOCs?

As the number of T\&H MOOCs increases, it may be helpful to introduce the existing experiences of instructors, so that we can better understand the situation, and identify problems that need to be considered in future developments.

\section{Literature Review}

\section{T\&H MOOCs and Relevant Studies}

Just as the number of MOOCs in the T\&H field is limited, so is the existing research on the subject. A search in Google Scholar on May 2, 2017 using the keywords "tourism" and "MOOCs" resulted in 18 relevant publications, including eight journal articles, eight conference proceedings' papers, and two book chapters.

The most relevant studies were from Deale (2015), and Annaraud and Singh (2017). The former study used a survey instrument to learn about 144 T\&H educators' understanding, perception, and usage of MOOCs. Deale's results showed mostly neutral or even sometimes negative perceptions of MOOCs. 
The latter study estimated the variance in perceptions of MOOCs between 45 students and 25 faculty members in the field of T\&H in the US using a survey instrument, and found a significant difference in 11 of 31 variables. The overall analysis of the 2017 study also showed that faculty members and students had favorable feelings toward the use of MOOCs. Considering that Deale's respondents were also mostly from the US (121 out of 144), it would appear that over the course of only two years, the general attitude of T\&H educators toward MOOCs had shifted from neutral/negative to positive.

Three publications reported results from their T\&H MOOCs' practices. Hara, Moskal, and Saarinen (2013) presented their six-week tourism MOOC to evaluate teaching effectiveness by analyzing data from six in-course quizzes, one final exam, and four during- and after-course surveys. They concluded that the MOOCs format can demonstrate promising outcomes, and that its teaching of complex content to massive numbers of people around the world can be effective. Lin, Cantoni, and Kalbaska (2016) followed the ADDIE model (analysis, design, development, implementation, and evaluation) to produce their first tourism MOOC. The same MOOC was further reported by Lin and Cantoni (2017) to describe and demonstrate an evaluation strategy based on the Kirkpatrick model (Kirkpatrick, 2006)-it delineates four levels of training outcomes: reaction, learning, behavior, and results.

To date, no study about T\&H MOOCs has been found that addresses the full experience of producing MOOCs as an instructor.

\section{Studies of Instructors in MOOCs}

Searching outside the field of T\&H, it is possible to find existing literature about instructors in MOOCs. For instance, interviews with eight MOOC instructors from the University of Toronto revealed six themes: instructors' motivations to offer MOOCs; MOOC design, development, and delivery; measures for success; development success; development support; and implications of MOOC instruction (Najafi, Rolheiser, Harrison, \& Håklev, 2015). Another study involved 14 interviews with MOOC instructors and reported three stages for each MOOC taught: preparation, implementation, and feedback (Zheng, Wisniewski, Rosson, \& Carroll, 2016).

Doherty, Harbutt, and Sharma (2015), basing their study on the experience of developing four massive open online courses, suggest that "designing and building a MOOC can be a huge undertaking so a clear workflow is essential to keep on track" (p. 178). For a clear workflow to emerge-so that results can be optimized-thoughtful planning and practices are usually required. Another shortcut is learning from the experiences of previous practitioners who have already gone through the process. However, most MOOC researchers have investigated the learners' perspective, which leaves a significant gap in the literature on the institutional threats and opportunities, as well as on MOOC facilitators' experience and practices (Liyanagunawardena, Adams, \& Williams, 2013; Ross, Sinclair, Knox, \& Macleod, 2014).

\section{DOI Approach to Study MOOC Experiences}

To understand the whole process of how MOOC instructors experience MOOCs as an innovation, we need a detailed framework that can elaborate on the actual implementation process at the individual adopter's level. This calls for the Diffusion of Innovations (DOI) theory by Rogers (2003). Why use DOI instead of another well-known model, such as the Technology Acceptance Model (TAM)? The reasons are twofold. The first consideration is how a model applies to the situation at hand. TAM is applicable to the individual level of adoption, when what is needed is a better understanding of the factors that influence an individual's decision to adopt a technology. DOI, on the other hand, offers a 
systematic framework to explore the relationship between technology and people and their interactions within a social system. It covers both the organizational level of adoption but also the intra-organizational level of adoption, which is not only subject to each individual's own will, but also influenced by organizational contexts. The second consideration is the research approach. TAM is a model offering a clear set of measurements for its major factors, such as perceived usefulness and perceived ease of use. These measurement features match perfectly with a quantitative research approach. In the theory system of DOI, its widely accepted model, Innovation-Decision Process (IDP), has proven to be efficient in exploring

the process through which an individual (or other decision-making unit) passes from gaining initial knowledge of an innovation (Knowledge), to forming an attitude toward the innovation (Persuasion), to making a decision to adopt or reject the innovation (Decision), to implementation of the innovation (Implementation), and finally to confirming this decision (Confirmation)." (Rogers, 2003, p. 168)

Moreover, IDP is perfectly suited to a qualitative research approach. A comparison of DOI, TAM, and IDP is presented in Table 1.

DOI was often adopted as the theoretical approach for MOOC studies related to student perception, student achievement, highly motivated students, higher education, online social worlds, and collaborative activity (Gasevic, Kovanovic, Joksimovic, \& Siemens, 2014). It also supported research investigating MOOC diffusion among HEIs. DeRousie (2014) examined four innovations including MOOCs through the lens of DOI by considering factors related to diffusion and adoption in higher education. The dataset of 81 institutions was used to investigate the diffusion of MOOCs in the US. When it comes to individual adopters-instructors who teach MOOCs-one study (Evans \& Myrick, 2015) surveyed 162 professors who had taught MOOCs, taking a DOI approach to better understand how MOOCs were perceived by instructors. On the strategic decision level, Murphy, HortonTognazzini, and Williams (2014) drew on the DOI theory and the tourism industry to investigate and propose two strategies for MOOC adoption and subsequent implementation.

However, no research has applied IDP to conduct an in-depth study of MOOC instructors' experiences of making decisions, implementing MOOCs with actions, and their intentions regarding whether to continue teaching MOOCs in the future. 
Table 1

A Comparison of DOI, IDP, and TAM

\begin{tabular}{|c|c|c|c|c|c|}
\hline & Level of adoption & Conditions to apply & $\begin{array}{l}\text { Applicable research } \\
\text { approach }\end{array}$ & Pros & Cons \\
\hline $\begin{array}{l}\text { Diffusion of } \\
\text { Innovations } \\
\text { (DOI) }\end{array}$ & $\begin{array}{l}\text { Organizational, } \\
\text { intra- } \\
\text { organizational, } \\
\text { individual }\end{array}$ & $\begin{array}{l}\text { To investigate the } \\
\text { maturity of an } \\
\text { innovation, the } \\
\text { different } \\
\text { levels/characteristics } \\
\text { of adopters, or } \\
\text { decision-making } \\
\text { process of an } \\
\text { innovation. }\end{array}$ & $\begin{array}{l}\text { Qualitative research } \\
\text { approach }\end{array}$ & $\begin{array}{l}\text { It can explore not } \\
\text { only relevant } \\
\text { elements such as } \\
\text { technology and } \\
\text { users but also the } \\
\text { process of } \\
\text { innovation diffusion } \\
\text { throughout the } \\
\text { social system. }\end{array}$ & $\begin{array}{l}\text { Difficult to quantify, } \\
\text { especially almost } \\
\text { impossible to } \\
\text { measure what } \\
\text { exactly causes the } \\
\text { adoption of an } \\
\text { innovation. } \\
\text { Meanwhile, cannot } \\
\text { account for all } \\
\text { variables. }\end{array}$ \\
\hline $\begin{array}{l}\text { Innovation } \\
\text { Decision } \\
\text { Process } \\
\text { (IDP) }\end{array}$ & Intra-organizational & $\begin{array}{l}\text { To explore the } \\
\text { decision-making } \\
\text { process of an } \\
\text { innovation. }\end{array}$ & $\begin{array}{l}\text { Qualitative research } \\
\text { approach }\end{array}$ & $\begin{array}{l}\text { The "process" } \\
\text { element from the } \\
\text { theory of DOI, with } \\
\text { detailed stages of } \\
\text { knowledge, } \\
\text { persuasion, } \\
\text { decision, } \\
\text { implementation, to } \\
\text { confirmation. }\end{array}$ & $\begin{array}{l}\text { Stages follow each } \\
\text { other in a time- } \\
\text { ordered manner, } \\
\text { which is not always } \\
\text { the case. } \\
\text { Difficult to quantify. }\end{array}$ \\
\hline $\begin{array}{l}\text { Technology } \\
\text { Acceptance } \\
\text { Model } \\
\text { (TAM) }\end{array}$ & Individual & $\begin{array}{l}\text { To investigate users' } \\
\text { perception of a } \\
\text { technology, in } \\
\text { particular tackling } \\
\text { with the perceived } \\
\text { usefulness and } \\
\text { perceived ease of } \\
\text { use. }\end{array}$ & $\begin{array}{l}\text { Quantitative } \\
\text { research approach }\end{array}$ & $\begin{array}{l}\text { A parsimonious and } \\
\text { powerful theory to } \\
\text { reveal a relationship } \\
\text { chain, having } \\
\text { beliefs influencing } \\
\text { attitudes, which } \\
\text { lead to intentions } \\
\text { and actual } \\
\text { behaviour. }\end{array}$ & $\begin{array}{l}\text { It has to be } \\
\text { integrated into a } \\
\text { broader one, which } \\
\text { would include } \\
\text { variables related to } \\
\text { both human and } \\
\text { social change } \\
\text { processes, and to } \\
\text { the adoption of the } \\
\text { innovation model. }\end{array}$ \\
\hline
\end{tabular}

\section{Research Questions}

Our review of the literature suggested a gap across three areas: IDP, in-depth studies about MOOC instructors' experiences and practices, and T\&H MOOCs. Furthermore, MOOC researchers have favored a quantitative research approach, while very few studies have used methods traditionally associated with a qualitative research approach (e.g., interviews, observations, and focus groups; Veletsianos \& Shepherdson, 2016).

Considering our research interests, past MOOC practices in tourism and the research gap in the literature, in this study we follow the IDP model and conduct in-depth interviews to explore MOOC instructors' experiences and perspectives when producing MOOCs in the field of T\&H. We include only three stages (adoption, implementation, and confirmation) from IDP, dropping the other two stages (knowledge and persuasion). The reason behind that decision was that our research interest was to identify common action-related experiences rather than to understand individual knowledge or inner thoughts affecting persuasion. Three research questions guided the process of this research:

- Why did instructors decide to adopt MOOCs in their professional career?

- How did instructors implement the MOOC innovation? 
- How is the confirmation of MOOC decisions among instructors after the MOOC implementation?

\section{Methodology}

Between July 1 and December 9, 2016, all 30 instructors from nine different HEIs who offered T\&H MOOCs between 2008 and 2015 were invited to participate in an interview. Six instructors, each from a different MOOC and university, volunteered and were interviewed.

The semi-structured interviews followed a protocol designed for this study, containing 13 open-ended questions. Interviews were conducted through Skype and recorded. The longest interview lasted 67 minutes, while the shortest one lasted 44 minutes. The average length of the six interviews was one hour.

An inductive approach was used to analyse the interviews' data (Creswell, 2012; Thomas, 2006) by: coding interviews and transcribing code segments relevant to research questions; collapsing codes into emergent themes and categories; corroborating interview data with other data sources; and preparing descriptive accounts of major and minor themes from the data.

\section{Results}

This section presents the major findings of the interviews as responses to the three guiding research questions.

\section{Why did Instructors Teach MOOCs?}

Four instructors did not autonomously decide to become MOOC instructors; the institutes' senior management decided to enter the MOOC market as providers, and once this occurred, these instructors were invited. Instructor 4 mentions that the first wave of MOOCs in his university were produced mostly due to pressure from senior management. However, he was glad that he took the challenge and went through this process because it opened a completely new world to him.

Sometimes MOOC platform providers invited universities to offer MOOCs on specific subjects, which was the case for Instructors 3 and 6.

They [platform's name] came with two different ideas: [subjects' names]. These are based on what people were searching for on [platform's name]. They did not have that course covered yet. They were looking for people with expertise in that area. They probably found us based on our [subject's name] activities, because we are very good in those areas. I just happened to be a good match between what interests them and what capacities we have. (Instructor 6)

Two instructors taught MOOCs on a voluntary basis. Instructor 1 chose to provide a MOOC because of his expertise and passion, with no support from the university. Instructor 2 volunteered to lead the MOOC experience after it was proposed by the head of the university.

The top three personal motivations mentioned by instructors to teach MOOCs were: institutional interest/pressure from the boss (five of six), trying MOOCs as a new technology/environment/tool for teaching (four of six), and sharing knowledge and subject matter expertise (three of six). 


\section{How did Instructors Implement MOOCs?}

One imperative aspect investigated by this study was the actual implementation process of producing a MOOC as an instructor: "Implementation occurs when an individual puts an innovation into use. Until the implementation stage, the innovation-decision process has been a strictly mental exercise of thinking and deciding" (Rogers, 2003, p. 179). In the current study, the implementation process included all actions by instructors after the decision to offer a MOOC. In the conversations, six stages plus one cross-phase element were identified: prepare, design, develop, launch, deliver, evaluate, plus support and train (Figure 1).

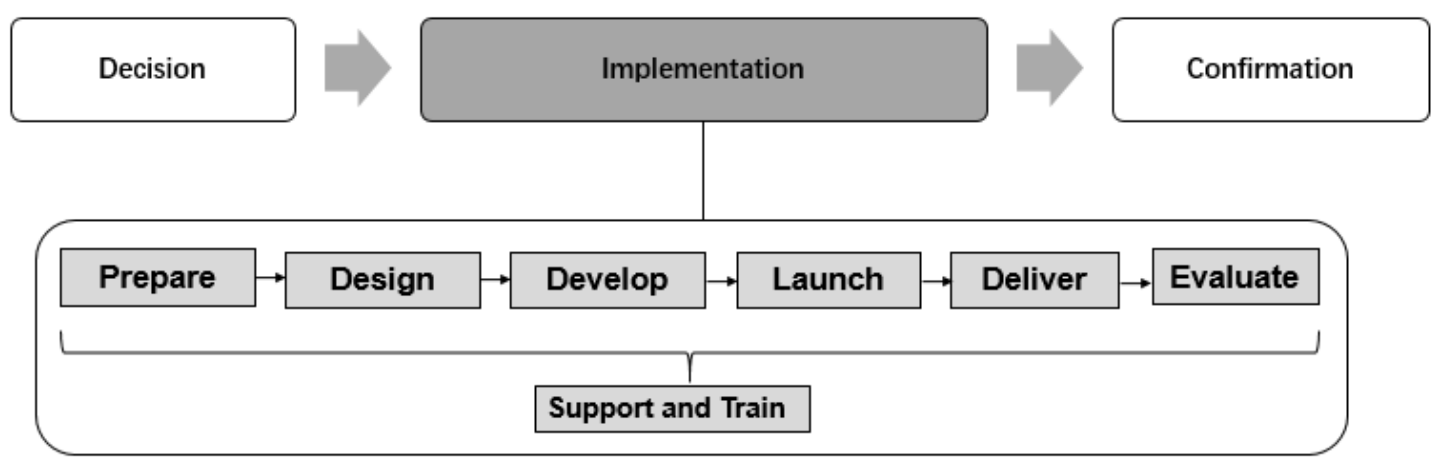

Figure 1. The implementation process of producing MOOCs: A map.

\section{Phase 1: Prepare}

Four instructors described the phase of preparation. Detailed actions in this phase were different among instructors. For Instructor 1, the situation was that there was only one instructor in the MOOC and no external support was available; however, the instructor had archived a rich collection of video materials from previous teaching of the topic, and these videos were reused in the MOOC.

Instructor 2 received enough money from the university to start the project but needed to recruit people and select a suitable MOOC platform as the first stage of work.

Two other instructors regarded the preparation phase as an opportunity to answer some basic yet critical questions before designing the detailed educational experiences, such as which level to teach, which topic to teach, how many videos to publish each week, and which activities to assign to complement the teaching.

Choose a topic. Four instructors said their MOOCs' topics were chosen by the universities because of the high reputation of those HEIs in the respective fields.

So the university approach was to choose, from each of the four faculties, one area of research and education strength and to develop a MOOC from that. There were five MOOCs initially launched. One is from my faculty. So basically, it is to choose something that the university has a high reputation for. (Instructor 5)

Also, two instructors shared that when choosing topics, they were more likely to avoid overlapping content with the work of other MOOC instructors already available online. 


\section{Phase 2: Design}

The design phase sets up the whole experience for the course's learners. You can think of it as the instructional design process. For Instructor 2, the instructional design of the MOOC was the result of a bottom-up approach with a lot of brainstorming sessions, which considered both the technical affordability and the observable effectiveness. This was possibly because his MOOC was the first MOOC experiment at his university, and hence there were no procedures already in place for such work.

Instructor 3, on the other hand, received strong and organized guidance to design his MOOC.

In the design phase, I was very much helped by them [a unit for the MOOC production at the university] in thinking of different pillars that I have to deliver. [...] I had this outline of the design and discussed the outline with them to verify my idea. After discussing with them, I went back to my original design and adjusted it. (Instructor 3 )

However, sometimes even with very strong support, the work is still challenging. Instructor 6 was supported by around 10 people during his MOOC experience. For him, the design process turned out to be "quite heavy and probably a part that many people did not realize [how heavy it can be]." $\mathrm{He}$ described this stage as a mixed process of both preparing for video recording (mainly scripting) and designing the entire experience.

\section{Phase 3: Develop}

Experiences of producing videos. Except for Instructor 1, all the other five instructors experienced the process of development, including the development of videos and other content. During the conversations, these instructors talked about their videos' development.

Instructor 3 found the whole process of producing videos very easy. Instructor 4 suggested that having an engaging personality helps during this process. They both perceived teaching in front of a camera as being "acting" and very different from the traditional face-to-face teaching.

You are now like a star on TV. Not everyone can become a TV star or movie star. [...] You need to be an actor when you are doing a MOOC. (Instructor 4)

Instructor 6, besides being an instructor, also served as "producer" and supervised several other instructors in his MOOC when filming video lectures. According to him, there was trouble that began in the video scripting stage, which then continued in the studio during recording and editing.

Sources of content used in MOOCs. Four of six instructors stated that the content used in their MOOCs was mainly reused or adapted from their previous teaching activities.

Instructor 2 said the content did not mirror the teaching being done on campus, but it was closely related to the research activities his team conducted in the university. Instructor 6 mentioned that because MOOCs serve a lower level of learning, his team had to cut down their postgraduate programs' contents to better fit the need of MOOCs. 


\section{Phase 4: Launch}

This stage comprises the process of assembling all the developed content and putting it on the platform in a structured way to make it accessible online. Five MOOCs were repeated after their first iteration, which usually had a fixed starting date. Instructor 2 stressed that promotion activities are to be done by the MOOCs' instructors before and after the launch.

Especially in the field of MOOCs, you need to be involved in terms of promoting the MOOCs, in terms of reaching out to the right audiences [...]. If it's corporate social responsibility and public relations after all, you need to reach the right public. So I was deeply involved in designing it and running promotional activities so as to make sure that we had contacts with hopefully interested people. (Instructor 2)

\section{Phase 5: Deliver}

Once online, the MOOCs enter the delivery stage, when various interactions happen within the course, as illustrated in Figure 2.

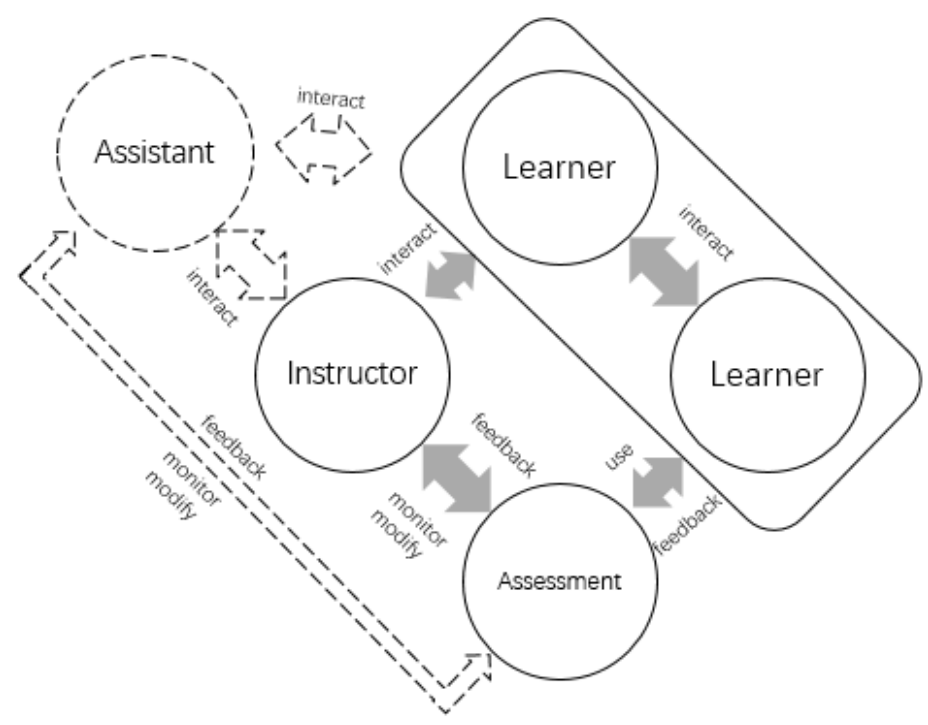

Figure 2. Interactions within a MOOC.

Intra-MOOC interaction: Online forums. All six instructors mentioned that their interaction with learners in MOOCs was mainly through discussion forums, either directly or through a teaching assistant.

Forums also made it possible for learners to interact with other learners. In Instructor 4's MOOC, a group of bilingual students volunteered to help another student whose English was not as strong.

Three instructors commented that the online forum as an interaction method was more than sufficient for them, and sometimes even too much.

Intra-MOOC interaction: Assessments. The interaction provided by assessments in MOOCs happens in an action-feedback loop. Some assessments are graded, such as quizzes, exams, and peer-review activities. Our interviews revealed that quizzes were often (all six MOOCs) used to measure learners' learning. Another method to encourage peer interaction is the peer-review 
assessment, where a learner is required to submit an assignment and will not receive grades on it until giving grades to a certain number of submissions from others. Two instructors used peer-review assessments in their MOOCs and positively recommended it. In the best-reported case of peer-review assessments, the instructor commented:

I had some concerns before about using peer-review assessments, but I think [platform's name] did a good job because they ensure us that it is going to work because it worked in the past. You have to make sure particularly the grading criteria is clear, unambiguous, objective, and it obviously requires a lot of planning and effort of the people who put together the exercises. (Instructor 6)

Extra-MOOC interaction: Email and social media. Two instructors described the email conversations they experienced with MOOC learners outside the MOOC platforms. Instructor 1 said that he received too many emails and had to beg learners not to send emails so often. Instructor 3 also received many emails but commented that learners just need to express what they wanted to express and that he had replied to all their messages.

When asked about their attitude toward using social media as a communication tool with learners, most of the instructors expressed concerns and considered social media to be unnecessary (or not requested). Instructor 2 was an exception, showing a positive attitude and describing positive experiences with using social media as a part of his MOOC (in particular a Facebook group and a dedicated Twitter hashtag).

Monitor and improve the quality. Besides the interactions that happen within and outside of MOOCs, the instructors need to monitor the online content-using direct observation, analytic data provided by their platform, or feedback from learners. Our interviews revealed that modifications were made as needed to correct mistakes or improve the teaching.

Flipped classroom. Flipped classroom is a format of using a MOOC to teach basic knowledge and allowing for in-class time to address higher-level educational activities. No flipped classroom case was reported in this study. However, half the instructors introduced materials and activities from their MOOCs into their face-to-face classes at universities.

\section{Phase 6: Evaluate}

In this study, evaluation of MOOCs refers to the performance assessment of MOOCs from the perspective of their providers. In our interviews, we found that an evaluation procedure at the institutional level was missing in all the studied MOOCs. This is possibly because these MOOCs were still in the experimental or pilot stage and HEIs were only exploring such possibility.

Four instructors, however, did mention course-level evaluation experiences. These instructors mostly used an online survey to collect feedback from participating learners. In one case, the instructor had a comparatively better-organized evaluation approach for the MOOC.

I was asking myself whether it was a good experience anyway but I had the other people to reflect on formalization of evaluation so we had sort of at the managerial level four major layers to evaluate MOOCs and our MOOC in particular, which are: corporate social responsibility, public relations, marketing, and research. (Instructor 2) 
When asked about the usage of analytic data in MOOCs, most instructors shared that they had plenty of data from MOOCs but did not have much time to use it, or only used it to monitor the quality of the course.

Four instructors discussed the gap between what they expected their pool of learners to be (when preparing their MOOCs) and what their actual pool of learners was. In fact, most instructors (four of six) tended to underestimate learners' backgrounds-especially their education levels-prior to delivering MOOCs.

\section{Cross-Phase Element: Support and Train}

Five MOOC instructors reported not receiving training from their universities. Four received training about the MOOC platforms directly from the platform providers. Only one instructor received some training from the central MOOC production unit in the university; this training was about how to design and teach MOOCs.

Five instructors were well supported by a team of four to ten people for the MOOCs' production. Three said that their MOOC experiences were under the guidance of a central unit from their universities, which took responsibility for supporting instructors when producing MOOCs.

Course assistants, available in four of the MOOCs, were often mentioned as being active throughout the whole process of MOOC implementation, especially during the delivery stage, where the mass communication with learners becomes a challenge to instructors. Like instructors, they had to frequently interact with learners and instructors, and were involved in assessment activities. Two instructors had no assistant, and they expressed difficulty in managing the course all by themselves without proper support.

\section{Findings on Re-Inventions}

Reinvention usually happens at the implementation stage (Sahin, 2006), which was described as "the degree to which an innovation is changed or modified by a user in the process of its adoption and implementation" (Rogers, 2003, p.180). Such efforts depart from the core or mainline version of innovation promoted by the change agency (Rogers, Eveland, \& Klepper, 1977). Rogers (2003) stated one general assumption about reinvention: the higher the re-invention rate is when implementing an innovation, the faster the innovation will be adopted. Most instructors chose to avoid risk in their adoption and implementation of the MOOCs, staying away from innovative teaching or learning activities. Only two instructors referred to some elements of their MOOCs as inventive. One reinvention was in the content delivered through video: instead of the instructor being a talking head in a studio or conducting interviews in an office setting, the instructor created a documentary film. Another re-invention came as a result of the instructor adopting animated and interactive media in the MOOCs.

\section{How is the Confirmation of MOOC Decisions Among Instructors After the MOOC Implementation?}

When asked "are you willing to continue teaching MOOCs in the future and why?" three instructors gave positive answers, while the other three were hesitant to continue teaching MOOCs. Instructor 6 stated that he would not repeat the experience unless it could become less demanding and more rewarding. The other two instructors firmly stated that they did not want to produce a new MOOC in the future, but that under certain conditions, they might consider re-teaching the existing MOOCs. 


\section{Discussion}

Through interviews with six instructors who taught T\&H MOOCs between 2012 and 2015, we aimed to explore the reasons or motivations for offering MOOCs, the process of developing MOOCs, and the intention to continue offering MOOCs in the future. In this section, we present our results in comparison with the previous literature, explain the current study's contribution and suggest future improvements.

Stressful but motivating. Every interviewed instructor reported the experience as having "taken a lot of time, a lot of hours," or being "overwhelming" or "difficult." Instructors from other fields also reported similar experiences (Egerstedt, 2013; Najafi et al., 2015). Considering all the stresses, why would instructors invest time and effort in something that could risk their reputations in the case of failure? T\&H MOOCs' instructors explained that their decision to teach MOOCs was mostly due to a request from the senior management. In the cases of personal motivation, the decision came from wanting both to experiment with MOOCs as a new technology for teaching, and to share knowledge on a topic about which the instructors are passionate and have expertise. Similar motivations were reported by instructors from other fields, for example, the wish to gain first-hand experience with MOOCs as a teaching tool (Egerstedt, 2013; Najafi et al., 2015), shaping the MOOC development in their specialism or subject (Egerstedt, 2013), and demonstrating the teaching of their host institute (Najafi et al., 2015).

Support is critical. The existence of a group of people who can dedicate their time, skills, and efforts to assist the various instructors who produce MOOCs at a university was considered effective and efficient. This institutional support, as a critical requirement when producing a MOOC (Corke, Greener, \& Philip, 2016), can positively influence the sustainability of the existing MOOCs over the long run by maintaining the communication with online learners no matter when they join the MOOCs. In other words, MOOC design and delivery is a team effort requiring ample emphasis on planning and clarity (Najafi et al., 2015). Other findings also confirmed the importance of adopting a team approach to producing a MOOC (Alario-Hoyos, Pérez-Sanagustín, Cormier, \& Delgado Kloos, 2014; Belanger \& Thornton, 2013; Corke et al., 2016).

The contribution of a map. Our study has revealed six critical phases of implementing and offering a MOOC, plus one cross-phase element. These six phases are: prepare, design, develop, launch, deliver, and evaluate; plus, across all phases-support and train. These reported stages were partially addressed in previous works (Najafi et al., 2015; Zheng et al., 2016). The current study narrates the details of the IDP model's "implementation" stage in the context of MOOCs by summarizing MOOC instructors' practical experiences into a visual flow map (Figure 1). The map breaks down the stages divided by other scholars into more detailed phases, which can be useful in the following ways: (1) as a timeline, the process map demonstrates the complete process of producing a MOOC from the perspective of MOOC providers. The timeline allows for greater understanding of the experiences of MOOC instructors, which had been a gap in the literature; (2) as a guideline, the process map provides a possible path for forthcoming MOOC instructors to follow, which can help to improve MOOC practices in the future.

Face the discontinuity. The combination of two facts-institutional interest being the main reason of their decision of adopting MOOC practices and the high discontinuity of instructors-could be explained by the DOI theory as: the authoritative decision style resulted in a lower possibility of repeating MOOC practices by the early adopters. According to Rogers (2003), the decision by an 
individual within an organization to adopt a particular innovation can be contingent (dependent on a decision made by others in the organization), collective (the individual can vote but eventually have to follow the group decision), or authoritative (the individual is told whether or not to adopt it). Authoritative decisions may increase the chance of initial adoption by individuals but may also reduce the chance that the innovation is successfully implemented and routinized (Greenhalgh, Robert, Macfarlane, Bate, \& Kyriakidou, 2004).

Under the top-down approach of MOOC adoption within a university, to reduce the discontinuity of instructors, the university can consider the suggestions by Rogers (2003), who described the IDP as a process to reduce uncertainty and proposed five attributes of innovations that help to decrease such uncertainty. These attributes include: relative advantage, compatibility, complexity, trialability, and observability. Universities can make full use of the support and training as a string through all six phases, to package the early adopters' practices with these attributes. Such attainment can not only sustain the existing practices but also showcase best practices to attract new instructors as later adopters.

Between borders. Three possible connections can be bridged between the two educational contexts: face-to-face and online. First, T\&H MOOC instructors adapted contents from their previous teaching, research, and practical activities to the context of MOOCs. This was the case with other MOOC instructors as well. By analyzing the mainstream MOOC platforms Coursera, edX, and Udacity, Yang (2015) found that the mainstream MOOC teaching mode is a continuation of the traditional curricular structure and the traditional teaching process. Second, assets built for MOOCs were introduced back to the face-to-face classroom, and became supplemental resources for students (Hollands \& Tirthali, 2014), to improve or enhance the face-to-face learning experiences. Third, the application of the flipped classroom (Cook \& Triola, 2014). Even not adopted in any T\&H MOOC, the flipped classroom practices have been reported and encouraged in other MOOCs (Chen, Yang, \& Hsiao, 2016; Lee \& Rofe, 2016; Li, Zhang, Bonk, Guo, \& Guo, 2015; Robinson, 2016). It is believed that by using blended learning or flipped classroom models, students can gain basic knowledge at their own pace through a MOOCs' high-quality content. As well, students can conserve their classroom time for learning experiences better suited to the social nature of a classroom, such as activities to deepen understanding, solve problems, encourage creativity, spark innovation, and train students in critical thinking (Anders, 2015; Ingolfsdottir, 2014).

Tools for interaction. As a built-in tool of the MOOC teaching format, the forum was highly valued by T\&H MOOC instructors as the way to interact with learners. This result is consistent with a previous study (Stephens-Martinez, Hearst, \& Fox, 2014), which surveyed 92 MOOC instructors and concluded that discussion forums were rated as the most useful resource for understanding class dynamics and preparing courses for the next iteration. "The ubiquitous online discussion forum has long been seen as a suitable place for asynchronous communication and discussion among participants on a large scale.” (Zhang, Skryabin, \& Song, 2016, p. 277); it is no surprise that the discussion forum fits perfectly into MOOCs, which host a mass audience globally.

By contrast, social networking tools did not receive positive feedback from T\&H MOOC instructors. Facebook and Twitter in MOOC settings has been frequently practiced and researched. Facebook has been used to access resources provided to deepen the understanding of course content, and to encourage connectivity, peer learning and interaction, and learning about current trends (Liu, McKelroy, Kang, Harron, \& Liu, 2016). Twitter has been used to connect peers and share information, 
such as resources or comments on their personal and real-time status (Lin, Hoffman, \& Borengasser, 2013). Facebook was found to have a greater impact than Twitter (Alario-Hoyos, Pérez-Sanagustín, Delgado Kloos, \& Munoz-Organero, 2014; Salmon, Ross, Pechenkina, \& Chase, 2015), and also more useful according to MOOC learners (Liu et al., 2016). MOOC learners also reported that the social networking tools had a positive impact on the social aspects of their learning process (Brownell \& Swaner, 2010; Dodge \& Kendall, 2004; Kassens-Noor, 2012) but they preferred to use the social medium to which they were already accustomed (Veletsianos \& Navarrete, 2012). T\&H MOOC instructors may need not only proper guidance and support on how to use social tools to facilitate communication, but also-possibly more importantly-to better understand that these tools are welcomed by learners and that they can help to improve social learning in MOOCs.

Re-invent to innovate MOOCs. MOOCs nowadays usually contain video lectures, quizzes, discussion forums, and sometimes peer-review assessments. Our interviews' results suggest that T\&H MOOCs did not typically go beyond these formats. The limitation in the pedagogy and effectiveness of MOOCs has been often discussed (Waldrop, 2013). Along with the fast development of web technologies, more and more widgets and applications emerge. The usages of various online tools in the MOOC context need further experimentation and research. For instance, it was suggested that for innovative teaching on the Internet, it would be interesting to add collaboration tools such as Google+ hangouts and shared documents to enable the fluid forming of study groups for some class types (Cerf, 2013). New ideas for the many uses of digital tools (Ingolfsdottir, 2014) can enrich the learning experience.

\section{Conclusions}

With the guidance of the IDP, we conducted semi-structured interviews with six HEI instructors who taught T\&H MOOCs between 2008 and 2015. Our results uncovered useful insights into these early adopters' experiences through the process of decision, implementation, and confirmation. We identified the top three reasons these instructors decided to teach a MOOC, which included institutional interest/pressure, learning a new teaching environment, and sharing their knowledge and expertise. Based on their descriptions, we created a panorama map of the process of implementing MOOCs for instructors. The map includes six phases-prepare, design, develop, launch, deliver, and evaluate-as well as one cross-phase element: support and train. It was found that reinvention was a rare case among T\&H MOOCs. After their MOOC teaching experiences, half the instructors were positive about continuing the experience, while the other half expressed hesitation and concerns.

The limitations of this study include a lack of discussion about the subject matter and pedagogy design of T\&H education in the context of MOOCs. Another limitation is that the sample size was small. However, our interviewees accounted for $20 \%$ of all instructors and represented $67 \%$ of all HEIs that offered a T\&H MOOC in the analyzed timeframe.

As an explorative study, this research sets an example to study MOOC instructors' experiences and perspectives with the IDP model. Future studies are needed, for example, to use the whole IDP model to study MOOC instructors, to include a larger sample of interviewees, or to apply the same approach to other subjects and compare the results. 


\section{References}

Alario-Hoyos, C., Pérez-Sanagustín, M., Cormier, D., \& Delgado Kloos, C. (2014). Proposal for a conceptual framework for educators to describe and design MOOCs. Journal of Universal Computer Science, 2O(1), 6-23. DOI 10.3217/jucs-020-01-0006

Alario-Hoyos, C., Pérez-Sanagustín, M., Delgado Kloos, C., \& Munoz-Organero, M. (2014). Delving into participants' profiles and use of social tools in MOOCs. IEEE Transactions on Learning Technologies, 7(3), 260-266. DOI 10.1109/TLT.2014.2311807

Anders, A. (2015). Theories and applications of massive online open courses (MOOCs): The case for hybrid design. The International Review of Research in Open and Distributed Learning, 16(6). DOI http://dx.doi.org/10.19173/irrodl.v16i6.2185

Annaraud, K., \& Singh, D. (2017). Perceptions of hospitality faculty and students of massive open online courses (MOOCs). Journal of Hospitality \& Tourism Education, 29(2), 82-90. DOI 10.1080/10963758.2017.1297714

Belanger, Y., \& Thornton, J. (2013, February 5) Bioelectricity: A quantitative approach: Duke University's first MOOC. Retrieved from http://bit.ly/2s92Iq2

Brownell, J. E., \& Swaner, L. E. (2010). Five high-impact practices: Research on learning outcomes, completion and quality. Association of American Colleges and Universities, 17. doi:10.1111/teth.12035/full

Cantoni, L., Kalbaska, N., \& Inversini, A. (2009). eLearning in tourism and hospitality: A map. Journal of Hospitality, Leisure, Sport \& Tourism Education, 8(2), 148-156. DOI:10.3794/johlste.82.263

Cerf, V. G. (2013). Running AMOOC. IEEE Internet Computing, 17(3), 88-88. DOI 10.1109/MIC.2013.53

Chen, S.-C., Yang, S. J. H., \& Hsiao, C.-C. (2016). Exploring student perceptions, learning outcome and gender differences in a flipped mathematics course. British Journal of Educational Technology, 47(6), 1096-1112. DOI 10.1111/bjet.12278

Cook, D. A., \& Triola, M. M. (2014). What is the role of eLearning? Looking past the hype. Medical Education, 48(9), 930-937. DOI 10.1111/medu.12484

Cook, M. (2016). State of the MOOC 2016: A year of massive landscape change for massive open online courses. Online Course Report. Retrieved from http://bit.ly/2qZbn1i

Corke, P., Greener, E., \& Philip, R. (2016). An innovative educational change: Massive open online courses in robotics and robotic vision. IEEE Robotics \& Automation Magazine, 23(2), 81-89. DOI 10.1109/MRA.2016.2548779

Creswell, J. W. (2012). Qualitative inquiry and research design: Choosing among five approaches. Thousand Oaks, California: Sage Publications. 
Deale, C. S. (2015). An exploratory study of hospitality and tourism educators' use and perceptions of MOOCs. Journal of Teaching in Travel \& Tourism, 15(2), 150-165. DOI 10.1080/15313220.2015.1026470

DeRousie, J. C. (2014). An exploration of the diffusion and adoption of four innovations in higher education. (Doctoral dissertation).Retrieved from https://etda.libraries.psu.edu/catalog/23568

Dodge, L., \& Kendall, M. E. (2004). Learning communities. College Teaching, 52(4), 150-155.

Doherty, I., Harbutt, D., \& Sharma, N. (2015). Designing and developing a MOOC. Medical Science Educator, 25(2), 177-181. DOI 10.1007/s40670-015-0123-9

Egerstedt, M. (2013). Controls for the masses [focus on education]. IEEE Control Systems, 33(4), 4044. DOI 10.1109/MCS.2013.2258762

Evans, S., \& Myrick, J. G. (2015). How MOOC instructors view the pedagogy and purposes of massive open online courses. Distance Education, 36(3), 295-311. DOI 10.1080/01587919.2015.1081736

Gasevic, D., Kovanovic, V., Joksimovic, S., \& Siemens, G. (2014). Where is research on massive open online courses headed? A data analysis of the MOOC Research Initiative. The International Review of Research in Open and Distributed Learning, 15(5). DOI 10.19173/irrodl.v15i5.1954

Greenhalgh, T., Robert, G., Macfarlane, F., Bate, P., \& Kyriakidou, O. (2004). Diffusion of innovations in service organizations: Systematic review and recommendations. Milbank Quarterly, 82, 581-629. DOI 10.1111/j.0887-378X.2004.00325.x

Hara, T., Moskal, P. D., Saarinen, C., \& Instructure, I. D., Sr. (2013, November). Preliminary analyses of a cutting-edge knowledge distribution method of MOOC (massive, open, online course) to teach tourism as an industry. Presented at the $3^{\text {rd }}$ International Conference on the Measurement of Economic Analysis of Regional Tourism, Medellin. Retrieved from http://bit.ly/2nHGcDz

Hollands, F. M., \& Tirthali, D. (2014). Why do institutions offer MOOCs? Online Learning, 18(3). DOI $10.1145 / 2556325.2566250$

Ingolfsdottir, K. (2014). Impact of MOOCs and other forms of online education [point of view]. Proceedings of the IEEE, 102(11), 1639-1643.

Kassens-Noor, E. (2012). Twitter as a teaching practice to enhance active and informal learning in higher education: The case of sustainable tweets. Active Learning in Higher Education, 13(1), 9-21. DOI 10.1177/1469787411429190

Kirkpatrick, D. (2006). Evaluating training programs: The four levels. San Francisco: BerrettKoehler Publishers. 
Lee, Y., \& Rofe, J. S. (2016). Paragogy and flipped assessment: Experience of designing and running a MOOC on research methods. Open Learning: The Journal of Open, Distance and ELearning, 31(2), 116-129. DOI 10.1080/02680513.2016.1188690

Li, Y., Zhang, M., Bonk, C. J., Guo, J., \& Guo, Y. (2015). Integrating MOOC and flipped classroom practice in a traditional undergraduate course: Students' experience and perceptions. International Journal of Emerging Technologies in Learning, 10(6), 4-10. DOI 10.3991/ijet.v10i6.4708

Lin, J., \& Cantoni, L. (2017). Assessing the performance of a tourism MOOC using the Kirkpatrick model: A supplier's point of view. In R. Schegg, \& B. Stangl (Eds.), Information and communication technologies in tourism 2017 (pp. 129-142). Cham, Switzerland: Springer. doi: 10.1007/978-3-319-51168-9_10

Lin, J., Cantoni, L., \& Kalbaska, N. (2016). How to develop and evaluate an eTourism MOOC: An experience in progress. e-Review of Tourism Research (eRTR), 7, 1-5.

Lin, M. F. G., Hoffman, E. S., \& Borengasser, C. (2013). Is social media too social for class? A case study of Twitter use. TechTrends, 57(2), 39. DOI 10.1007/s11528-013-0644-2

Liu, M., McKelroy, E., Kang, J., Harron, J., \& Liu, S. (2016). Examining the use of Facebook and Twitter as an additional social space in a MOOC. American Journal of Distance Education, 3O(1), 14-26. DOI 10.1080/08923647.2016.1120584

Liyanagunawardena, T. R., Adams, A. A., \& Williams, S. A. (2013). MOOCs: A systematic study of the published literature 2008-2012. The International Review of Research in Open and Distributed Learning, 14(3), 202-227. DOI 10.19173/irrodl.v14i3.1455

Miralbell, O., Cantoni, L., \& Kalbaska, N. (2014). The role of eLearning applications within the tourism sector. ELC Research Paper Series, 8, 4-5. Retrieved from http://elcrps.uoc.edu/elcrps/index.php/elcrps/article/view/2285.html

Murphy, J., Horton-Tognazzini, L., \& Williams, A. (2014). Exploring effective diffusion of tourism and hospitality MOOCs. In C. Schott, K. Caton, \& C. Herzog (Eds.) Proceedings of the Eight TEFI Conference (TEFI8) 'Transformational Learning: Activism, Empowerment and Political Agency in Tourism Education'. Guelph, Canada (4-7 June 2014): Tourism Education Futures Initiative (pp. 190-202).

Najafi, H., Rolheiser, C., Harrison, L., \& Håklev, S. (2015). University of Toronto instructors' experiences with developing MOOCs. The International Review of Research in Open and Distributed Learning, 16(3). DOI 10.19173/irrodl.v16i3.2073

Robinson, R. (2016). Delivering a medical school elective with massive open online course (MOOC) technology. PeerJ, 4, e2343. DOI 10.7717/peerj.2343

Rogers, E. M. (2003). Diffusion of innovations. New York: Simon and Schuster. 
Rogers, E. M., Eveland, J. D., \& Klepper, C. A. (1977). The innovation process in public organizations: Some elements of a preliminary model. Executive Summary of the Final Report. Department of Journalism, University of Michigan.

Ross, J., Sinclair, C., Knox, J., \& Macleod, H. (2014). Teacher experiences and academic identity: The missing components of MOOC pedagogy. Journal of Online Learning and Teaching, 10(1), 57. DOI 10.1080/02680930701754047

Ryan, P., Horton-Tognazzini, L., \& Williams, A. (2016). A snapshot of MOOCs in hospitality and tourism. Journal of Hospitality \& Tourism Education, 28(2), 107-112. DOI 10.1080/10963758.2016.1163497

Sahin, I. (2006). Detailed review of Rogers' diffusion of innovations theory and educational technology-related studies based on Rogers' theory. TOJET: The Turkish Online Journal of Educational Technology, 5(2).

Salmon, G., Ross, B., Pechenkina, E., \& Chase, A. M. (2015). The space for social media in structured online learning. Research in Learning Technology, 23. DOI 10.3402/rlt.v23.28507

Siemens, G. (2013). Massive open online courses: Innovation in education. In R. McGreal, W. Kinuthia, \& S. Marshall (Eds.) Open educational resources: Innovation, research and practice (pp. 5-15). Vancouver: Commonwealth of Learning and Athabasca University. Retrieved from http://bit.ly/2fttu8V

Stephens-Martinez, K., Hearst, M. A., \& Fox, A. (2014, March). Monitoring MOOCs: Which information sources do instructors value? In Proceedings of the First ACM Conference on Learning@ Scale Conference (pp. 79-88). ACM.

Thomas, D. R. (2006). A general inductive approach for analysing qualitative evaluation data. American Journal of Evaluation, 27(2), 237-246. DOI 10.1177/1098214005283748

Tracey, J. B., Murphy, J., \& Horton-Tognazzini, L. (2016). A framework for evaluating MOOCs in applied hospitality and tourism settings. Information and Communication Technologies in Tourism 2016 (pp. 667-679). Cham, Switzerland: Springer .

Veletsianos, G., \& Navarrete, C. (2012). Online social networks as formal learning environments: Learner experiences and activities. The International Review of Research in Open and Distributed Learning, 13(1), 144-166. DOI 10.19173/irrodl.v13i1.1078

Veletsianos, G., \& Shepherdson, P. (2016). A systematic analysis and synthesis of the empirical MOOC literature published in 2013-2015. The International Review of Research in Open and Distributed Learning, 17(2). DOI 10.19173/irrodl.v17i2.2448

Waldrop, M. M. (2013, July 17). Education online: The virtual lab. Nature. Retrieved from http://www.nature.com/news/education-online-the-virtual-lab-1.13383 
Yang, L. (2015, November). Dilemma and development strategy of MOOC localization. In Information Technology in Medicine and Education (ITME): $7^{\text {th }}$ International Conference on Information Technology in Medicine and Education (ITME) (pp. 439-442). IEEE.

Zhang, J., Skryabin, M., \& Song, X. (2016). Understanding the dynamics of MOOC discussion forums with simulation investigation for empirical network analysis (SIENA). Distance Education, 37(3), 270-286. DOI 10.1080/01587919.2016.1226230

Zheng, S., Wisniewski, P., Rosson, M. B., \& Carroll, J. M. (2016, February). Ask the instructors: Motivations and challenges of teaching massive open online courses. In Proceedings of the 19th ACM Conference on Computer-Supported Cooperative Work \& Social Computing (pp. 206-221). ACM. DOI 10.1145/2818048.2820082

\section{Athabasca} University 